\title{
When Didactic Drama Meets the Comical: Two Views on the Victorian Family
}

\author{
Max von Blanckenburg
}

\section{Introduction}

"We live $[\ldots]$ in an age of ideals" - with this statement Gwendolen in The Importance of Being Earnest (21) makes a most vital observation about the time and culture she lives in. In Victorian England, people were indeed confronted with clear-cut ideals of social life regarding both the public and private sphere. In this context, it was the nineteenth-century home and family playing a particular role as the "crystal of society" and "nucleus of national character" (Smiles 394). Hence, family was the very core of Victorianism serving to regulate its members' behaviours and demanding absolute obedience. In line with this, Sarah Stickney Ellis states in 1843: "it is evident that principle, rather than inclination, must form the basis of our actions" (210).

These principles, now, have received quite varying responses, for instance, on the Victorian stage. In this thesis, I will examine Oscar Wilde's The Importance of Being Earnest and George Bernard Shaw's Mrs Warren's Profession ${ }^{1}$ as two plays mirroring the prevailing conceptions of nineteenth-century family life in two different ways. What we find in both plays are characters that show awareness of the social

1 In the following, the two plays will be abbreviated as IBE and MWP. 
expectations that are connected to the family. Their forms of dealing with these expectations, however, differ fundamentally in IBE and $M W P$, as I will demonstrate. Drawing on the field of New Historicism, these illustrations of family on stage can then be linked to Shaw's and Wilde's criticisms of Victorianism. Shaw was a member of the Fabian society and as a dramatist "hoped to effect direct social change" by means of a moralistic theatre (Marshik 47). With strong didactic elements in his drama, he aspired to lament a system that caused social injustices. This clearly sets him apart from Wilde, who had a distinctively comical approach to depicting society.

It does not come as a surprise, then, that examiners and scholars of the time, in turn, reviewed the two plays rather differently: the social criticism in Shaw's drama was fairly obvious and even resulted in a yearlong ban from the stage. As to $I B E$, however, the play was referred to as "extraordinarily funny" (Fyfe 99), on the one hand, and "intangible" (Archer 97) for its lack of a moral point, on the other. Notably, Bernard Shaw found even harsher words for his Irish fellowcountryman's work. From his perspective, Wilde's play was "heartless" and "hateful" (Shaw 1918, 95f) and watching it was merely a waste of time (Shaw qtd. in Eltis 173).

However, Oscar Wilde for himself considered comedy as a most suitable format to convey a message without being restrained by censorship (Wilde 305). His biography reveals that he was a man who was at odds with Victorianism in various respects, and so we can ask if in his drama there is a dimension beyond the mere comical. According to Reinert, the key to realising the subversive power of Wilde's humour in the play is to understand that "the quip is not a quip; it means what it says" (15). Against this background, the following analysis will show that, when taking the characters in IBE seriously, there is much more to find than the witty humour of a Restoration comedy.

Ultimately, it will become clear that, despite their different styles, Shaw and Wilde actually are on a similar mission: for one thing, they ask the question as to what happens when family members thwart social expectations in Victorian England. For another, both make clear that this human failure cannot simply be attributed to individuals' shortcomings but likewise blames the social system behind it. Therefore, it is the aim of this paper to explore these ways in which Shaw and Wilde form their perception of Victorian ${ }^{2}$ society and its felt deficits into two, on the surface, very different plays, and, beyond that, to examine the possible functions of these social criticisms.

2 Knowing that within the nineteenth century there were, in fact, a number of cultural developments with regard to the notion of family and the roles of men and women, what can be done within the scope of this paper is to outline that intersection of values and ideas that was valid and relevant for the better part of the century and embodied by Queen Victoria. Therefore, the expressions 'nineteenth century' and 'Victorian age' are not meant to provide a detailed and adequate description of the whole century but rather touch upon the major cultural discourses. 


\section{Theoretical Foundations}

\subsection{New Historicism}

Especially in an age like the late nineteenth century, bringing about changes to society in many various ways (such as, for instance, through industrialisation or far-reaching social reforms), it is highly interesting to focus on how the respective social conventions of the time are taken up and mirrored in literary works. In order to do so, it is necessary to adopt an analytical perspective that allows making a statement about the relationship between literature and the context in which it originates. The framework of New Historicism is very suitable here because it provides a viewpoint from which it situates literature within its given social and historical context. Thus, it enables me to show, on the one hand, how interwoven both $M W P$ and IBE are with Victorianism and, on the other, how the two plays draw attention to the destructive potential of social convention for the lives of individuals.

Generally, New Historicists like Stephen Greenblatt claim that any literary work bears a connection to "other [cultural] practices, behaviour and values" (Robson 18) and is hence per se embedded in a sociocultural context. The nature of this link, however, is in no way straightforward but becomes an object of study. Thus, opposing a materialist view, Greenblatt criticises the idea that a text merely represents its context or vice versa (Greenblatt 1982, 5). Rather, literature can be understood as part of a "network of material practices" (Veeser xi), and, as such, a literary work holds a specific position within a larger structure encompassing, amongst others, social and political forces. This description is reminiscent of Clifford Geertz's semiotic approach to culture: according to him, an author - just like any other person - is suspended in self-spun "webs of significance" (Geertz 5), that is, their culture. Any literary creation is thus done, quite literally, out of this position and also reacts upon it. The aim of New Historicism is, now, to combine the interpretation of literature and history (Gallagher/Greenblatt 3) and leverage the fact that the former cannot be examined, let alone explained, without the latter.

What is more, New Historicism understands neither literature nor its sociocultural context as static. Instead, both are seen as variables taking an influence on and even producing each other reciprocally. That is, if culture fully permeates the process of writing a text, it inevitably provides the "social understandings" upon which that very work depends (Greenblatt 2005, 12) and thus strongly influences its creation. In turn, texts of any kind are considered to contain a "social energy" that impacts on their readers and, in turn, on the views and behaviour of those readers (Robson 22, 71). Hence, literature interacts with its cultural setting and, furthermore, has the capacity to invoke changes through its readership or audience, respectively. 
What is of particular importance to this paper is Greenblatt's assumption about the origin of that social energy, namely, some kind of dissatisfaction on the part of writers: in his opinion, authors "are agents whose lives are not quite lived in harmony with the official, generalised, and objectively recoverable version of their society" (During 179). I will claim later on that this is very true for both George Bernard Shaw and for Oscar Wilde. In MWP, Shaw, very obviously, voices his criticism of a society that makes prostitution possible and even reasonable. Oscar Wilde, in a more humorous manner, renders social conventions absurd and hence expresses his concerns implicitly. In the last chapter, I will state that both playwrights even go one step further than just expressing their lamentations by including indications towards an alternative and better social reality in their works. To examine this mutual enrichment of the two theatre plays and their well-defined social world, New Historicism provides a valuable analytic tool.

\subsection{Gender Theory}

As a second theoretical component for this thesis, Gender Studies will allow me, in combination with New Historicism, to analyse how Shaw and Wilde use family ideals and dynamics as essential building blocks for their plays. One of the reasons for this is that from today's state of research, we can say that gender was an elementary category for Victorians to structure their lives by (Shires ix) and particularly their families. Evelyn Glenn claims that any discussion about, for example, a nineteenth-century woman's position in the family, in fact, represents a discussion about her position in society (348). If gender is one of the main factors for the formation of Victorian family roles, then by analysing gendered familial structures and positions, we likewise gain an insight into the underlying social system and hence draw a line from Gender Studies back to New Historicism.

In order to name the key points in Gender Theory that are relevant here, one can start by defining gender, according to Judith Butler, as the "cultural interpretation of sex" (10). Rather than relating to the biological traits of a person, the term gender is hence linked to the attribution of socio-cultural features to a sexed body. In this context, Butler would agree with Greenblatt on saying that culture is always man-made ${ }^{3}$, which is the reason why gender roles, in turn, are by no means natural but equally constructed. Amongst their functions is that these roles serve as a public carrier for social convention and behaviour (cf. Hess/Ferree 16), which will be of particular importance when analysing the family members in the two authors' plays. On the surface of gender, people (or in this context: characters) literally act out a social discourse that is - at least traditionally - dominant in their society and by iterating that performance affirm and reproduce a specific social code (Butler 185ff).

3 Greenblatt uses the colourful expression of the "poetics of culture" to illustrate this (cf. Robson 29). 
This brings us directly to the topic of this thesis: I will apply the notion of gender to the Victorian family by interpreting (core) family as a cultural unit smaller than society that, yet, functions by means of similar social mechanisms, such as gender performance. Glenn supports this thesis - that we can think of family roles as one realisation of gender - by maintaining that gendered structures develop, above all, amidst members of a family through their social intercourse (348).

The critical point here is that the adherence to this Victorian family gender system acts as a precondition for someone's participation in social life. That is to say, while gender is, in fact, a cultural construct, its artificiality is carefully hidden (Butler 198) and its performance is turned into a social requirement. Now, in social sciences it has been claimed that although, theoretically, individual genderinconsistent behaviour could lead to the altering or even dissolution of a gender category, in point of fact, it rather excludes that person from the very gender concept (Deaux/Kite 109f). With regard to both $M W P$ and IBE, it will become clear that all those aspects - the unnaturalness of gender, its characteristic performativity in the family and the consequences of gender-deviating behaviour - are at the heart of the plays' claims and criticisms. Despite the obvious differences between the two literary works, it emerges that the authors both seem to formulate the same question as Butler: "What interventions to this ritualistic repetition are possible?" (199). Interestingly, it will become clear in the analysis that their answers to it do not vary as much as one might think.

\section{And What About the Context?}

\subsection{Of Roles and Duties - The Victorian Family}

If the two dramatists, as a matter of fact, used the gender conception of Victorian family as an object of subversion, then this label must have had some sort of identifiable substance that audiences would be able to relate to. In how far this holds true, however, depends on the angle from which we look at family: Mintz points out that "there was, of course, no single Victorian family type" (xi). Certainly, there is merit in the argument that those familial gender relations were in reality not one-dimensional but diverse. Nevertheless, what Shaw and Wilde allude to are the major cultural discourses, which, although revolving around a strongly idealised version of family, were present in the minds of people at the time.

Strikingly, in spite of the fact that a huge majority of $85 \%$ belonged to the working class, the prevalent ideology and role models were disseminated via the middle class and from there percolated down into the lower ranks of society (Nelson 2007, 6). Again, there were, surely, class differences regarding family ideals but rather in the sense that the working classes could often not afford to uphold the 
same standards as the middle classes, mainly because they were involved with numerous other duties that were of higher importance. ${ }^{4}$

\subsubsection{Family Values and the Value of Family}

Under Queen Victoria's reign, the notion of family was very much that of the social fundament that would provide a structure to both individuals' lives and likewise society as a whole. Hence, family had a number of inner and outer functions: for its members, it constituted a counter-part to the large and dangerous world of work, a safe place that people could retreat to and that was therefore paramount in a Victorian's life (Ittmann 142). While social change was, in many ways, happening at a fast pace, family was seen as something constant and of timeless quality (Nelson 2007,6 ). To the outside world 5 , in turn, family had a strong representative side: by creating a new family, through marriage, an individual was allocated his or her own position in society. One was no longer seen as being under the influence and patronage of one's parents but would take up a specific - and publicly identifiable - place within the social system of Victorian England. Since this new unit was to operate on the same principles as society, family, effectively, turned into a "microcosm of the larger social and political world" (Mintz 60).

This social logic is a key factor also with regard to any form of literary creation in general: as conventionality was crucial for Victorianism, any representation of family in art was to cast a positive light on society and thus reaffirm the dominant and politically desired social patterns.

In this context, we find certain characteristics to be central in giving shape to that cultural construct that is the Victorian family, and acting as behavioural guidelines for its members: the middle class code of conduct was essentially built around "dignity, work and duty" (Gordon/Nair 5). That is to say, there was a distinct allocation of tasks and responsibilities that Victorians would fulfil with as much earnestness and conscientiousness as in any way possible. Hereby, everyone would prove acceptance of their part within the social framework of family, and consequently of society. In order to illustrate what this meant in practice, this paper will consider the different members of the Victorian core family: mother, father and the relationships to their children.

\footnotetext{
4 For further information on the relation of class and family roles in the nineteenth century consult Nelson 2007.

5 Historically, this process of creating a clear distinction between the public and private world rooted in the nineteenth century development that, for the first time, the sphere of work was no longer located in and associated with the home (Flanders xxii).
} 


\subsubsection{Family Roles}

What is pivotal regarding nineteenth-century family roles is that there was a strict gender division into two different spheres that men and women would occupy. These gendered domains constituted their respective members' lives and likewise did the men and women (re-)constitute them, which resulted in the production and reproduction of publicly visible gender effects.

Those effects can be seen perhaps most clearly in the role of the mother, who virtually constituted the heart of the nineteenth-century family. Judith Flanders, for instance, even goes as far as describing the home not as "a place, but [as] a projection of the feminine" (xxxi). When thinking back to the idea of duty in Victorianism, one can sense the high responsibility that was laid on the mother regarding the inner and outer functioning of family. There is no doubt that bringing up the children was one of her major obligations (Mintz 59) but the notion of the Victorian mother encompassed a great deal more than that. She was likewise ultimately accountable for the whole family's welfare regarding its moral and social renown (Ittmann 154). This included managing the household and keeping property and family members presentable at all times. Furthermore, "purity, devotion, and selflessness" (Nelson 2007, 27) were amongst the central virtues that a woman was to possess. Her own being - sometimes idealised as angelic ${ }^{6}-$ in this thinking radiates that goodness over husband and children and hence uplifts them morally. Strikingly, however, when looking at nineteenth-century prescriptive literature, such as conduct books ${ }^{7}$, there is little reference to the necessities and preferences that she herself might have. Sally Shuttleworth traces this back to the Victorian idea that a woman's emotions were all and exclusively tied to her role as a mother, to the effect that the concept of Victorian womanhood fully merged into that of motherhood (32). Although there might be truth in her argument, I would object to it in as much as there was a definitive second facet to a woman's gender role, namely, that of the wife.

In fact, only within marriage a woman could fulfil her mother role at all because having children out of wedlock was an utter social taboo and usually had far-reaching consequences. By marrying, however, a woman would secure or possibly improve her societal position and she would complete her identity through the attachment to a male counter-part. As a prominent writer of her time, Sarah Stickney Ellis paints this picture of marriage and highlights two vital sides of it: on the one hand, marriage is described as the most significant step to take in the life of a woman. Not only does it ensure that one is being provided for, it also promises marital love as the greatest good anyone can obtain on this planet $(21,107)$.

\footnotetext{
Most prominently featured in Coventry Patmore's The Angel in the House, from 1854.

As for conduct books and manuals on how to organise home and family life, especially for middle-class women, see, for example: Isabella Beeton's The Book of Household Management (1861) or Sarah Stickney Ellis's series The Woman of England, The Wives of England, The Mothers of England, The Daughters of England (as of 1839).
} 
Likewise, however, Ellis appeals to her readers to be fully aware of the clearly inferior position that a woman has to take up compared to her husband, irrespective of her talents or achievements. Hence, she must always thoroughly examine a potential marriage partner in advance, in order to reassure herself of his integrity and her own will to fully subordinate herself (14). Moreover, as a fundament for this concept of femininity serves the regent herself, "our beloved QUEEN [sic] [in whom] we have the character of a wife and a mother" (12).

From this description of a Victorian woman, two conclusions can be drawn: Firstly, because it is the queen, representing all of England, who acted as a role model and thus set a dominant gender standard, one can argue that there was a role awareness across classes. This makes it possible to examine and interrelate Kitty Warren and Lady Bracknell later on. Secondly, referring back to New Historicism, one gets an idea of the vast influence of the socio-cultural and political forces on the lives of individuals, here on women. It does not come as a surprise then that these very determinative notions of femininity are mirrored within literary works.

Turning now to the second constituent part in the family, the father and husband, we once more find a variety of prescriptive statements regarding the set of desired character traits for a man. Interestingly, there are several overlaps between the gender roles of a man and a woman. For instance, the attribute angelic was likewise used in connection with an ideal man and related to him being strongminded and full of integrity (Ellis 58). Similarly, at first glance there seems to be some kind of gender competition between husband and wife considering that the expression 'head of the family' can be found for both partners (Farningham 10ff; Ellis 250). However, this potential contradiction can be resolved by looking closer at the two domains men and women occupied: while the wife would classically be in charge of intra-familial matters, it was the husband who protected the family from the outside world and likewise represented them to it. Therefore, he was the one to bear the highest authority as well as responsibility and consequently deserved to be treated with utmost respect (Ellis 67). To question this paternal authority was virtually unthinkable, especially because of the prevalent idea that it was divine providence giving a father his leading role (Mintz 60). In turn, it was part of his duties to provide financial security to a family as well as behaving in a morally impeccable manner (Ruskin [s. p.]). Generally, many of those desired masculine behavioural characteristics revolved around the notion of the gentleman as someone characterised through, amongst other things, suave manners, probity and benevolence. Those virtues were to be practiced in the family by any man irrespective of his financial background (Nelson 2007, 35) and thus separated the gentleman from belonging exclusively to a particular class. ${ }^{8}$

8 There is, of course, much more to be said about the notion of the Victorian Gentleman. Consider, for example: Newman, John Henry. The Idea of a University. London: Longmans, Green and Co., 1907. 
As a third point, by throwing light on the social structures that regulated how many Victorian sons and daughters lived together with their parents, we can see a more complete picture of the nineteenth-century core family which will be fundamental for the analysis of the two dramas. Broadly speaking, children, as well, were subject to various cultural forces that would strictly define their gender roles and require an everyday performance of them. The roles of sons and daughters differed in as much as there were different life paths sketched out for them, namely, to step into their respective parent's role at some point. Therefore, the longtime goal of the upbringing of sons was that they would preserve or ideally enhance the family's social and financial status (Nelson 2007, 72), just like the father did. As a consequence, within the phase of adolescence, sons would gradually gain more authority, which in many cases led to conflicts. Notably, these very tensions contained a social function: according to Mintz, "filial rebellion [was] one of the patterns through which cultural values were transmitted from one generation to the next" (88). That is to say, usually; father and son did ultimately not fall out with each other but both played their parts within the process of gender role transition that a growing-up son went through.

In comparison to a Victorian son, who was generally given more liberties to cultivate and prepare himself for independence, a daughter would be tied much more closely to the home (Nelson 2007, 86). Even more than any of her brothers, she had to be absolutely obedient and greatly care about her flawless angelic appearance and reputation in family and public (82). This was of utmost importance because a good name significantly enhanced her chances to find someone to marry and since she was considered to step into her mother's role at some day, marriage was obviously the key prerequisite.

\subsubsection{Cracks in the Social Foundation}

When considering Victorian family, it is important to note that there was, as a matter of fact, always some kind of discrepancy between gender demands and their fitting into the realities of people. Arguably, Shaw and Wilde had a sense for those two sides and, as will be shown, playfully hint at them in their works.

To start with, there is evidence that Victorian families and marriages did in many cases not live up to the prevalent gender claims (Gordon/Nair 70), either because people were not able to or did not want to. In fact, there is some truth in both: as for the first one, it was a broad social change - leading to "conflicts between work and home, between the needs of children and the limits of parents and between men and women over resources and sexual power" (Ittmann 142) that made it immensely difficult to conform to the high social expectations. Likewise, however, gender concepts were deliberately challenged and objected to by people: Gordon and Nair state that, within the course of the century, family and marriage ideals were increasingly questioned even though an actual altering of that 
long-established concept was still a long way off (97). Nevertheless, this criticism led to the emergence of at least one prominent alternative gender image: Victorians feared that the classic female gender role would change towards what was termed as the "New Woman" (Nelson 2007, 67) at the end of the century. This type of woman demanded education for herself, had career aspirations and showed traits such as smoking cigarettes, all of which were conventionally considered masculine features. As a result, the traditional feminine gender role was questioned and the masculine one even threatened.

I is only possible to touch upon this theme within the scope of this thesis, but nevertheless it allows the following conclusion: The fact that gender attributions can be dynamic because society is always in motion, supports Butler's thesis that these roles are by no means innate. On the contrary, people's belief in them is the result of a socialisation and education into a certain culture and - as history suggests - can be questioned and disrupted when those dominant discourses are at odds with the possibilities, needs and wishes of many.

\subsection{Censorship of Victorian Drama}

With respect to New Historicism, it is worth considering another cultural factor before actually looking into MWP and IBE: in nineteenth-century England, an overt and central dimension of the cultural influence on drama was, in point of fact, restriction through censorship. As English drama, for the longest time, had been staged at court and for the respective governments (Stephens 37), it is hardly surprising that these institutions considered it necessary to scrutinise theatre. On the one hand, censorship, therefore, was a means to channel creativity into a direction that complied with the state ideology, and, on the other, to punish those who would not put up with that policy. In this sense, it was an important powermaintaining instrument, even more so because the Victorian theatre enjoyed great popularity not only at court but it was also that very form of art with the largest mass appeal (2). Thus, if potentially subversive ideas could be widely disseminated via theatre performances, then drama had the power to do harm to "key social institutions" (Shellard et al. 43), amongst which the Victorian family is of particular interest here.

It was the task of the Lord Chamberlain and his examiners not to restrain but rather to protect drama (5). In their own view, only through their work, peace and quiet in society and family could be guarantied (Robert Southey, qtd. in Stephens 38). However, the censors' authority was not free from criticism either and since they naturally did not want to evoke the impression of suppressing creativity and art as such, there was often a fine line between the alleged protection of theatre and its audiences, and an immoderate social straightening of the stage.

For playwrights such as Oscar Wild and George Bernard Shaw, it was hence of utmost importance to have a sure feeling for what they were allowed to write or 
what had better be left out. Remarkably, however, there was not always consensus between examiners as to what specifically was to be termed 'inappropriate' or 'indecent'. While scenes of nudity and obvious political criticism were commonly cut out, as for the toleration of morally and socially deviant behaviour on stage, the extent of censorship lay very much in the hands of a particular licenser (Shellard et al. 46, Stephen 80f). This is a key point to keep in mind when analysing Wilde's and Shaw's works. While both writers' biographies suggest that they were clearly not at ease with Victorianism in various respects ${ }^{9}$, they were not able to simply flout the nineteenth-century drama conventions and voice their discomfort freely. Therefore, instead of openly deploring a socially unjust system, the two writers had a chance to utter criticism by illustrating how those circumstances impinge upon the lives of individuals, and families in particular. Hence, they were able to question social categories upon which society depended to a great deal. In fact, it will become clear that the way the dramatists display family roles on stage is highly subversive and ultimately targets not only family but society as a whole. Thus, what would certainly not have been possible to express directly is disguised in the plays through the altering of family ideals as a much subtler and more implicit method of criticism ${ }^{10}$.

\section{$4 \quad$ Families and Fallacies}

In this chapter, I will show how the characters in both plays present and represent, through their attitudes and actions, social truths that are strongly at odds with nineteenth-century family ideals. That is to say, the plays highlight, in two different ways, the discrepancy between generic family gender role prescriptions and people's diverse realities of life. Hess and Ferree argue that "because the gender system is not a reflection of natural differences, creating gender is a struggle" (16). We will see that this is accented in the two dramas in several ways.

The characters do not manage or do not choose to act according to convention and hence alter family conceptions. Through this deviation, a new light is cast on Victorian gender performance, revealing its artificial core and depicting the outcomes of socially inconsistent behaviour. While both playwrights make use of

9 Within the limits of this paper, there is no room to go deeply into the dramatists' biographies. Rather, as was claimed in 3.1.3., based on the two plays I will render visible the cultural embeddedness of the dramas and the perceived social injustices that they deal with. However, to read up on Shaw's and Wilde's biographical relationship to Victorianism consider, for instance: Belford, Barbara. Oscar Wilde. A Certain Genius. London: Bloomsbury, 2000; Jones, Howard Mumford. "Shaw as a Victorian." Victorian Studies: A Journal of the Humanities, Arts and Sciences 1 (1957): 165-172.

10 Being aware of the problems Shaw had with receiving a licence for Mrs Warren's Profession, and also of Oscar Wilde's downfall after the revealing of his homosexuality, I will not further dwell on the historical details in view of the fact that both plays were, in fact, staged after all. 
family as their object of subversion, their characters' actions, however, draw very different consequences: as will become clear in the following analysis, in MWP, Shaw has gender deviance punished whereas Wilde characters defy social demands by escaping into comical absurdity.

\subsection{Deconstructing the Victorian Mother}

\subsubsection{Kitty Warren}

Drawing on what has been said about family roles earlier, Allan states that a Victorian woman "craves to be a mother, knowing that she is an imperfect undeveloped being, until she has borne a child" (35). As for Kitty Warren, however, the facts are slightly different: she is a woman who happens to be a mother but has evidently not 'completed' her identity because she has born a child. On the contrary, $M W P$ is a play abounding with the idea that Kitty has a very different understanding of her own role. Whilst being fully aware of traditional Victorian mothers' features, she claims an alternative way to fulfil her motherly function and hence attempts to recreate her own gender role.

The first step in this process is her vigorous protest against gender convention. She knows very well what is "expected from a woman" (MWP 68) but blatantly communicates her opinion that mere conformity is socially utterly vacuous and more "hypocrisy" (ibid) than anything else. In her view, a woman - if not from a privileged social background - can only live up to the morally impeccable female gender image to the extent that her circumstances allow her to (64f). ${ }^{11}$ As her low social rank did not provide enough shelter and financial security, she feels she had to choose a different path than that of gender obedience. It is notable that Shaw's description of Kitty Warren completely opposes the classic Victorian view of Sarah Stickney Ellis, who emphasises the possibility and duty to always do "the greatest amount of good with the smallest pecuniary means" (201f). But suffering for the sake of upholding a gender concept that Kitty perceives as artificial anyway is not what Shaw's protagonist chooses to do.

Instead, to embark on a career in an area that could not be further away from Victorian ideals, Kitty redefines a female gender concept and grounds it upon two pillars: wealth and her own conception of character. In her discussion with Vivie it becomes clear that Kitty regards money as a necessity that a woman has to generate herself if male provision fails. She abandons that feminine labelling of being forever attached to a husband and sees her career as the only way to take a step out of that victimised position and towards self-determination (MWP 66f). At the same time, it appears to be crucial to her to keep her character morally upright.

11 We find a similar reasoning in Bertolt Brecht's Der gute Mensch von Sezuan, in which the protagonist Shen Te describes her dilemma by saying: "Gut zu sein und doch zu leben zeriss mich wie ein Blitz in zwei Hälften" (139). 
Remarkably enough, though, for Kitty Warren, keeping one's integrity is not a matter of reputation but mainly of self-respect (67f). Only through this shift from social to self-approval she can justify her business towards herself and Vivie. From that position she claims to "know how to treat [her] own child" (40) because, in her view, Kitty has deconstructed a flawed motherly ideal and rebuilt a new one.

Nevertheless, from a Victorian gender perspective her actions constitute a remarkable form of deviation, which, as Shaw's storyline suggests, will inevitably take its toll: to start with, the strong link between the vital notions of home and femininity is completely taken apart through her constant absence in her daughter's life. As Kitty was always tied up with business matters, Vivie does not feel her mother has reared her at all (37). It is very telling that Kitty's character is by no means as family-oriented as expected: while society wants her to understand "family devotion as the answer to the woes of public life" (Nelson 2007, 6), Kitty rather claims her own liberties and seems to be entirely taken up in her profession. Her statement "I must have work and excitement" (MWP 102) illustrates very well, for one thing, her priorities and, for another, how that business life has transformed her personality. Hence, a woman in her position cannot morally uplift anybody but instead has centred her actions on traditional masculine values and aims in life. Here we find a character movement towards that, among Victorians infamous image of the New Woman at the end of the century, who through her own profession "undermine[s] patriarchal and familial authority" (Ittmann 223).

Again, dedicating most of your time and passion to the world of work would clash with those Victorian values of maternal selflessness and familial devotion even if Kitty's business had been one of higher social acceptance. Even more so, running a chain of brothels - a fact that can only be hinted at but never spelt out in the drama - cannot stay without consequences in Shaw's play. Therefore, the image of Kitty as a strong, resolute woman is gradually deconstructed in the course of the plot. For instance, she herself realises she is not impervious to Frank's advances and has to acknowledge "I am wicked" (MWP 50), thus showing both surprise about her own lack of moral control and likewise awareness of her non-conformity with gender standards. In addition, when Kitty "embraces her daughter protectingly, instinctively looking upward for divine sanction" (69), it becomes obvious that the belief in her own mother role is not as firm as one might think. As a consequence, the more she anticipates that she has lost credibility in the eyes of Vivie, the more she attempts to take the bull by the horns: knowing that she has failed setting Vivie an example of a virtuous mother, Kitty tries to regain her family position by being authoritative and enforcing a motherly attitude $(54,59)$. This is entirely paradox, however, because she tries to bind her daughter by resorting to the family ideal that she has deconstructed herself! This is why her claim "You've no right to turn on me now and refuse to do your duty as a daughter" (103) does not have much effect on Vivie, who shakes off all family expecta- 
tions as she perfectly knows her mother is by no means in the position to demand gender conformity of her.

Furthermore, this raises a central question: What is the reason why Kitty suddenly enforces a quasi-motherly attitude and wants to determine Vivie's life so much? ${ }^{12}$ Arguably, it dawns upon her that she has fundamentally failed as a mother and hence fears to more and more lose significance as Vivie's parent. Her vehement begging "You wouldn't - you couldn't leave me" (63) supports this idea and, as a matter of fact, reveals strikingly reversed dependencies at this point of the play: a mother, traditionally being in charge of all matters within the family and wielding authority over her children, is suddenly abandoned by her much more autonomous child and cannot bear the thought of having to look after herself. From a reader's point of view, this is a most bitter ending, particularly because it does not even seem bitter to Vivie (104).

To sum up, the following conclusions can be drawn: There is potential for a harsh social criticism in the drama regarding the Victorian mother's gender role. On the one hand, we find that it is the circumstances that hinder Shaw's protagonist from being an ideal mother. In line with this, Marshik states that the perhaps most shocking observation about MWP is that Kitty Warren's choice of a career as a brothel owner seems to be a reasonable one considering her situation (49). That is to say, society does not actually give all of its members a chance to confirm gender prescriptions in practice and therefore fosters a social disparity. On the other hand, however, through the imperfect Kitty Warren, Shaw hints at the fact that this family gender ideal is entirely artificial anyway. Women who cannot or do not want to recognise this, in Kitty's view, possess, if anything, a "want of character" (MWP 67). She, however, is fully aware of the unnaturalness of these gender claims and hence denies their legitimacy. Yet, the tipping point of all this is that Kitty's story is not one of a successful emancipation from social demands. In the end, she has become "a coarse woman, a vulgarian by nature" (Nelson 1971/1972, 365) despite any attempts to recreate herself gender-wise. She fails at her prime duty to oversee a well-functioning household, in fact, in two ways. Outwardly, she cannot represent her motherhood to society and is hence not socially accepted. Inwardly, she does not offer Vivie a gender role to grow into but has indulged in a world with values so different from her daughter's that the two of them have entirely lost common ground, which leads to an inevitable parting.

\subsubsection{Lady Bracknell}

While it is fairly evident that Kitty Warren does not succeed in her family role, as for Wilde's Lady Bracknell, we have to look at her from a different angle. Just like

12 Cf. "Your way of life will be what I please" (MWP 61). 
Shaw's femme fatale is aware of her gender failure, Lady Bracknell, in turn, is perfectly certain about her unquestionable conformity, and hence will be examined against this background. To start with, one can state that Lady Bracknell has a very distinct and confident self-image, which she constructs through her selfperceived adherence to prevalent social norms and values. Hence, there is merit in the argument that she is virtually presented as the impersonation of society (Eltis 177). Indeed, there are frequent references to this very society that one must "never speak disrespectfully of" (IBE 83), illustrating her conviction to uphold the social status quo by all means: she praises the failure of English education that is securing her privileged position (25), sees the French revolution as an "unfortunate movement" (29) and generally disapproves of "arguments of any kind" because they are "vulgar and often convincing" (91). Thus, from her speech, which is ruling out any form of social criticism we get the sense that she has completely adopted Victorian society's fundamental thinking patterns as her own identityforming maxims.

In line with this, she likewise expresses strong opinions about family. To her, what is true on a larger scale, equally applies to the familial community: "strange coincidences are not supposed to occur" (91). As she considers her gender performance flawless, she sets high standards for others, too, and, for instance, seems to have her nephew Algernon fully under her thumb (cf. 17). Similarly to Kitty Warren, Lady Bracknell is even more commanding when it comes to her daughter's behaviour: she claims absolute authority as a mother and expects Gwendolen to be obedient at all times (24). In her own view, she fulfils her motherly role in that she herself serves as a role model protecting her daughter from any outer influences and at some point is going to select a husband for Gwendolen.

However, Lady Bracknell's character resembles that of Kitty Warren in an important point: there is a vital mismatch between the women's self-perceptions and their factual success in family matters. Although Lady Bracknell states to have "brought up [Gwendolen] with the utmost care" (29), her idea of rearing children does neither fully comply with Victorian standards nor does it ultimately pay off. Absurdly, she wants to protect her daughter's innocence by having her live in town and not in the countryside (26), which entirely opposes Victorian logic, even more so in a time of industrialisation. Her basic problem is that she tears down her self-given image of a "really affectionate mother" (25) by aiming all her actions not mainly at her child's welfare but at her idea of social conformity. Hence, just like she always tries to be close to where social power lies, Gwendolen is not supposed to live in a remote area in the countryside but must stay in town where society's heart is, in her mother's opinion. It is evident that bringing up kids for Lady Bracknell is therefore mainly (or perhaps solely) based upon the idea of securing the family's social and financial status. Therefore, she first cannot allow Jack's engagement to Gwendolen because he does not know about his social origin but has been found in a train station. This fact causes Lady Bracknell's 
comical fear that her daughter would possibly "marry into a cloak-room, and form an alliance with a parcel" (29). It is striking that the value of love is here completely neglected and subordinated to social pragmatism. ${ }^{13}$

Furthermore, in addition to constraining her motherly love, she likewise sacrifices her alleged high maternal morality in a number of ways: firstly, honesty does not seem to be one of her greatest qualities as she lies to her husband (78) and recommends Cecily to do the same about her age (85). Moreover, she maintains not to be in favour of "mercenary marriages" which is obviously counteracted by the fact that she only approves of Cecily after knowing about her fortunes (82f). Lastly, when Jack reveals Algernon's deceptions, Lady Bracknell simply decides to "overlook [her] nephew's conduct" (85) for the sake of financially alluring prospects coming with marriage.

What is more, Jack's and Algernon's comments highlight that her reputation is not as stainless as she claims either: while the former perceives her as "perfectly unbearable" and "a monster", her nephew even considers Lady Bracknell not to have "the remotest knowledge of how to live" (30). That this evaluation is not completely made out of thin air can be seen when looking at the relationship with her daughter again, which allows us to once more draw a parallel between IBE and MWP: much in the same way as Vivie is not obedient to Kitty, Gwendolen only pretends to be submissive to her mother (20). Thus, we again find a mother who, in this case, is not critical of but full of praise for society, but nevertheless fails in providing her daughter a gender role to grow into.

Still, we have to acknowledge that these deviations are presented in a very comical way throughout Wilde's play. This impression is even strengthened as Lady Bracknell's (at least partial) failure as a mother stays without any serious consequences for herself and her relationship with Gwendolen, which constitutes a fundamental difference to MWP. Nevertheless, I will argue the case that, in addition to this very humorous style, there is potential for social criticism also in IBE. Reinert supports this idea by saying that Lady Bracknell, like other characters as well, assumes "a code of behavior that represents the reality that Victorian convention pretends to ignore" (15). If this is true, we have got to ask what the nature of this undesired reality is, which brings us back to the cracks in Victorian gender imagery: it is the notion that nineteenth-century gender attributions are not innate but culturally constructed that is exemplified in the character of Lady Bracknell. She exaggerates her adhering to social demands and likewise proves her sense for their artificiality when she notes that behaving well and feeling well virtually excludes each other (IBE 17). Here we also see that this allegedly ignored reality is actually hinted at under the veil of humour. What seems merely comical at first glance in Wilde's world can, in point of fact, contain critical truths that expose

13 The topic of love and marriage will be dealt with in greater detail in chapter 4.4. 
both "hypocrisy and $[\ldots]$ the unnatural convention that necessitates hypocrisy" (Reinert 16f).

Therefore, one can take up Geertz's image again to say that Lady Bracknell is caught in Victorian webs of significance that dictate her actions, and yet, as they leave no room for flexibility, enforce her flight into comical exaggeration. The notion of home in IBE is then - again - not a projection of the feminine but rather a downscaled version of society that is completely overacted and hence ridiculed. Thus, Oscar Wilde seems to ask the following: if not even a woman of Lady Bracknell's position does live up to Victorian motherly ideals, then how can those ideals be legitimate after all?

\subsection{Failing Fathers and Missing Husbands}

Turning now from the analysis of mother figures to their male counterparts, we find a seamless continuation of gender failure. One of the two major aspects in this respect is the notion of failure through absence, featured in both plays.

Starting to examine $M W P$, it is far from trivial to note that Vivie lacks a father figure. If Kitty and Vivie's father had married or if he had taken on responsibility for his child, the familial situation would, of course, have been fundamentally different. Since Shaw did not choose the story to go that way, the family has to bear dire consequences: there is no one to provide financial support, which leads to Kitty's expanding rather than giving up her business to afford her living standard (MWP 100). As described above, Kitty develops rather masculine character traits, arguably because there is no husband who would carry these features in her stead. Furthermore, she leaves no doubt about her low opinion of men in general and hence is "determined to keep the child all to herself" (42). As a result, however, the small family obviously misses that masculine part representing them to the outside world and serving as the moral complement to Kitty. Likewise, the fact that Vivie is not protected by her father gives Crofts the chance to pursue his desire to approach her and even to put her under pressure (80).

In IBE, in turn, there is, as a matter of fact, not a single male parent present anyway. Gwendolen's father is only mentioned by Lady Bracknell but she does not even intend to tell her husband of their daughter's marriage plans, as she has never "undeceived him on any question" (IBE 78). Since he does not meet his gender role expectations to bear the highest responsibility and authority in the family, his wife is free (and also bound) to rule entirely according to her disposition.

Regarding the two dandies in the play, it is notable that neither Jack nor Algernon ever got to know their fathers $(27,94)$. This brings up the question if there is a connection between their unconventional characters and the lack of paternal influence, especially in light of the fact that within a father-son relationship cultural values were thought to be passed on across generations (cf. 3.1.2). Both their 
moral flexibility, vividly illustrated by their Bunburying, and their denial of any form of duty and responsibility could, in this sense, be ascribed to a missing masculine gender role model. In turn, this would explain why Jack, having no father himself, does not seem to be an ideal substitute father for Cecily from a Victorian perspective either (32).

Examining now the second aspect of paternal failure, we find - mainly in the character of Reverend Gardner - a strong form of gender deviation, not through absence, but rather in his attitude and actions. ${ }^{14}$ Although he is a rector, Gardner does by no means comply with an ideal father figure and indeed fails in both his profession and his family. To begin with, he seems to be aware of the paternal authority and respect that he is entitled to when he claims full powers to decide about his son's marriage plans (MWP 52f). However, Shaw thwarts the notion of a parallel between godly and fatherly authority straightaway: Reverend Gardner is a churchman who has got a past with Kitty Warren and thus has given up his high moral position once and for all. Even when he is being open and rueful about his faults, it becomes obvious that in the world of this play, there is no room for repentance or reconciliation.

The central and striking observation here is that Gardner's father role is deconstructed through the eyes of his son Frank. It is him who blatantly questions his father's integrity when he criticises the reverend for his excessive drinking (72). Likewise, Frank accuses Gardner of not fulfilling his duty as a clergyman (73), which is revealed as a profession that he never wanted to practise anyway (44f). By Victorian standards, this description of Frank, who feels a strong need to distance himself from the man who is supposed be a role model for him, casts a very poor light on Gardner's gender performance. This is even emphasised by the fact that we once more find a parent being dependent on a child in performing a gender role: the reverend needs his son to invent excuses in order to uphold the image of hospitality towards guests, and is even obedient to Frank's instructions (74). Here, the idea of a strong-minded father representing the family to the outside world is entirely torn to pieces.

Ending this chapter, the analysis of fathers in the two plays leads to one conclusion: when paternal figures are absent or fail in their role, family is fundamentally disrupted and gender deviation even spreads amongst family members. In the following, it will be shown that there are references between parental failure and the behaviour and mindsets of the children in both dramas.

14 In IBE, there is one reference to this active fatherly failure as well: Lady Bracknell comments on Jack's father, who "was essentially a man of peace, except in his domestic life" (95). 


\subsection{Rebellious Children}

\subsubsection{Vivie Warren}

Right at the beginning of the play, Shaw introduces Vivie Warren as a Victorian daughter with rather unconventional passions and priorities. Through Praed, we get to know her as a firm young lady being immersed in her work (MWP 31). She leaves no doubt about her dutiful and determined attitude, which is mirrored in both her appearance and behaviour. Her plain dress, strong handshake and scorn for art are some of the features symbolising that she is a fairly unusual character for a woman of her age and status $(32,36)$. To Vivie, womanhood is to be productive and efficient (35), rather than merely being a beautiful and well-mannered public display of her family's social rank.

Remarkably, the gender picture that is painted of her in the play resembles that of a Victorian son much more than that of a daughter. The values that she proclaims as pivotal to her identity - "purpose, [...] character, [...] grit" (56) - are amongst those that usually an adolescent young man was to develop when growing into his father's role. Similarly, her liking of whiskey, cigars and detective stories contribute to this rather masculine image (35). Furthermore, we see that Vivie has much more self-confidence and authority than a typical nineteenth-century daughter would ever be granted. This brings her into a conflict with Kitty, which is reminiscent of those father-son arguments transferring Victorian values to the filial generation (cf. 3.1.2).

However, in acting out these non-classical traits, Vivie strays from the prevailing gender rules, just like her mother did before her. As Kitty committed the social crime of abandoning her motherly role expectations, her daughter does not find a gender role laid before her that she is willing to adopt. Practically, she has never been tied to the home in a Victorian sense anyway because she has lived without a mother ever since. The fact that the two never built up a strong relationship seems to make it easy for Vivie to not only deny Kitty her filial support (MWP 33), but also to contradict and openly act against her (37). Instead of showing the socially expected absolute obedience of a daughter towards a parent, Vivie claims independence and refuses any values that her mother tries to pass down to her (101).

As a result, however, it appears she loses a great deal of her familial emotionality and sense of belonging: the question "Are you my mother?" (62) seems to have yet another dimension than merely asking about her own biological origin. One gets the impression that, on a deeper level, Vivie questions if there is anything left that would hold the two women together. Although both their biographies have come to be deeply rooted in the world of work, mother and daughter find only very little common ground. Instead, it emerges that the lack of motherly rearing has developed a necessity for gender recreation in Vivie. Strikingly, however, the 
result of this process is that Vivie adopts neither her mother's nor society's image of a well-bred daughter. She has developed into a woman who finds meaning and structure for her life in a reputable but clearly masculine profession. Hence, Vivie cuts herself loose from both her mother's moral decay as well as from society's concept of an angel-like feminine daughter.

Yet it is by no means the case that she remains untouched by this situation. In fact, there is no doubt that family is a markedly sore point in Vivie's character. Admittedly, on the one hand, she does show a resolute side of her personality when throwing all responsibility for Kitty overboard (103). On the other hand, though, it becomes clear that, beneath the surface, the dysfunctional relationship to her mother does indeed affect Vivie deeply (64). For only a moment in the play, she allows herself some familial empathy with Kitty and even changes her mind about her mother's infamous profession temporarily ("You are stronger than all England", 68).

However, the vital point to make here is that these rudiments of reconciliation are only very short-lived and do not undo Vivie's filial rebellion in any way. When she proposes "to be good friends now" (69), it becomes evident that for Kitty there is no chance of regaining her motherly role. If anything, they could meet on an equal footing as friends but the re-establishment of old familial gender hierarchies between mother and daughter seems absolutely out of the question.

What is it then that one can conclude from Vivie's socially untamed gender and the patterns of her behaviour? First and foremost, we find that in the drama's logic, gender discrepancy must again lead to far-reaching problems. As Vivie has never had parental role models on the part of either mother or father, she escapes into the working world and there finds a substance for her gender identity. However, as a consequence, she gives up her daughterly femininity and further loosens the already shaky connection to her home. This rebellion against family ideals, in Shaw's moral theatre, does not lead to happiness, though. Vivie herself reveals the ironic irreversibility of her situation: "I am my mother's daughter" (102). Although she has expended great effort to make something different of her legacy, in the end even cutting all ties to Kitty leaves open if there is fulfilment to be found for Vivie Warren. In any case, that ultimate parting between the two women throws an enormously poor light on Victorianism: the social circumstances in which both of them had to manoeuvre their ways through life did not leave any chance for family bonding but tore apart that most significant relationship between mother and daughter.

\subsubsection{Frank Gardner}

Earlier it was argued that it is Frank Gardner who through his disrespectful behaviour towards the reverend undermines the gender role of his father. In this chapter, I now want to focus more deeply on the question where this disobedi- 
ence comes from and what the consequences of Frank's actions are for himself and his family. Drawing on the analysis of Vivie, we can say that just like her gender role is negotiated through the conflicts with Kitty, Frank, similarly, has to be examined in light of his father because Gardner's paternal failure proves to be character-forming for his son. That is to say, the self-confident attitude that Frank shows towards several characters is, in actual fact, not built upon his own merits but on the hierarchical vacuum that Gardner's poor gender performance has caused. This allows Frank to escape from fatherly authority and control, and to live a dandy-like life that is first of all aimed at pleasure. Interestingly, in his lighthearted nature he does not "care a rap" about "social position" (45) and hence never really takes his own gender breach to heart. However, his lifestyle unmistakably suggests that Frank's first priority is certainly not to uphold his family's social and financial status, as would be his duty. He rather spends his father's money and when having to move back into his parental home merely explains that "things came to a crisis" (43). The "personal indulgences" (Ellis 64f) that Frank demands, however, would traditionally be granted only to the breadwinner in a family and honour a man's responsibility. It is obvious, though, that Frank has not earned the liberties he is given in this way: he does not cultivate himself or grow towards being an independent and self-sufficient man (cf. 3.1.2.), but instead seems happy to play the role of an ineducable child.

Furthermore, he does not give great care about is family's reputation either, which is best reflected in the way he speaks about the reverend: Frank is absolutely honest about his father's lack of skills as a pastor (MWP 55), instead praises his mother's intellect (59) and even depicts Praed, who is not a family member, as a much better father figure (59f). Although this criticism is, of course, directed at Gardner, it tells us a great deal about Frank's family gender role as well: Mintz describes very aptly that in Victorian families one could observe the "feverish attempts of a son $[\ldots]$ to define a distinctive personal identity while maintaining continuities with the past" (88). This is the very dilemma that Frank is caught in. $\mathrm{He}$ is in need of a gender role that would help him succeed in social and professional life but clearly does not want to step into that of his father. Hence, in order to develop his identity as an individual, he has to distance himself so much from his home that, in order to do this, the link to the reverend had best be cut off completely. However, we find at least two reasons that prevent him from taking this step: on the one hand, Frank does not seem to have the skills to earn a living on his own, but rather gambles with the money he has (MWP 88). On the other, he himself utters one of the key sentences in the play, that is, "Can't help it [...]: it runs in the family". This is the central idea that we have already found in the Kitty-Vivie conflict: Shaw's characters are inextricably linked to their parents and if those parents go astray, gender deviation is reproduced across generations. Therefore, it appears to be almost straightforward that Frank has to fail as a Victorian son. 
To sum up, it has become clear that he lacks obedience and respect towards his father, likewise a sense of duty and does not even feel the need to act according to social prescriptions. Admittedly, in comparison to Vivie, he does not completely fall out with his parent, which will be of importance later on (in Ch.5). Nevertheless, as he does not show any sense of responsibility, he surely fails as a son and likewise as a potential husband for Vivie. He is obviously not able to provide financial security for anyone or to take over a moral representative function for a family and hence from a Victorian perspective is far away from fulfilling the demands of both a son and a marriage partner.

\subsubsection{Gwendolen}

In comparison to Frank, we find Gwendolen to be a Victorian adolescent who knows very well about the expectations that are laid on her and likewise how important it is to conform to them. This is, of course, very much in line with her mother, who, above all, strives to confirm gender conventions. However, when looking closer at their relationship, it is questionable whether Gwendolen really has that "simple, unspoiled nature" (IBE 26) that Lady Bracknell proclaims. Despite Algernon's remark that "all women become like their mothers" (31), there is evidence that Gwendolen very much reframes the gender role that is presented to her through Lady Bracknell. Surely, her mother thinks and expects Gwendolen to be tied closely to the home but it becomes quite clear that there is some discrepancy between the Lady Bracknell's perception of her daughter and the actions of the latter. As a matter of fact, Gwendolen disobeys her mother repeatedly, which, strikingly enough, does never lead to any punishment or consequence (cf. e.g. 17, 20, 54). She hides her love to Jack (literally) behind Lady Bracknell's back, talks to her in a "reproachful" manner and, when Jack proposes to her, Gwendolen even tells her mother: "this is no place for you" (24).

Here we see that Oscar Wilde's play works quite differently compared to that of his moralising colleague: Gwendolen can always get away with these trespasses simply because she masters the skill of keeping up appearances, which disguises her intentions and clearly sets her apart from Frank in MWP. To the outside, she confirms Lady Bracknell's authority ("Certainly, mamma", 20) and seems keen to prevent that her mother would ever lose her face because of her. However, Gwendolen's behaviour reveals that she does not plan on stepping into that motherly role at all. Rather, she is able to see through her mother's conformist educational aims and, out of that position, manages to undermine them. Gwendolen knows Lady Bracknell "has brought [her] up to be extremely short-sighted" (61), and that not merely literally: she has realised that "it is part of her [mother's] system" (61) to keep her within reach, that is to say, under the influence of her own gender radiance. Therefore, as long as Lady Bracknell believes in Gwendolen's full dependence on that motherly judgement and influence, then, outwardly, 
that Victorian gender system is confirmed. Gwendolen's personality, however, makes plain that she considers this construct rather shallow and has learned to bluff her way past it without attracting attention.

In the same way, when other characters are present she declares that there are "principles at stake that one cannot surrender" (77) and yet we constantly find her thwarting Victorian ideals: she talks back to Algernon and even lectures him (34), thus clearly reversing the traditional gender hierarchy between them. Furthermore, she is described as "always refusing people" and hence "ill-natured" (30), and later in the play completely breaks with Victorian thinking when she claims that "in matters of grave importance, style, not sincerity is the vital thing" (76).

To sum up, what all this suggests is that Gwendolen actually has a sense for the fact that those Victorian gender demands are artificial, and, for her, consequently not to be followed per se. But as she is brilliant at concealing her role refusal, Wilde allows her to succeed as a cleverly disobedient daughter.

\subsection{Undermining Love and Marriage}

To gain a deeper insight into the plays' criticisms, it is worth casting light on the notions of love and marriage from a different perspective again: Both works play with the fact that marriage was to be that everlasting bond holding together the Victorian family and hence society as a whole. Interestingly, we hear a great deal about marriage in both plays but do not actually see anything of it. Although the topic runs like a golden thread through the two dramas, there is no depiction of a married couple whatsoever. What we do find, however, are a number of characters with different needs and ambitions in respect to love and wedlock that are representing strongly varying attitudes towards Victorian thinking. For instance, quite contrary to the nineteenth-century idea of love as a counterpart to worldly and work-related matters, marriage is termed as "demoralizing" in IBE (6) and in $M W P$ not even the clergyman leads a fulfilling married life (59). By analysing the central characters, it will be shown that on the basis of humour, on the one hand, and lamentation, on the other, Wilde and Shaw once more draw upon prevailing ideas and ideals, and ultimately make a mockery of them.

\subsubsection{The Refusal of Marriage}

While the relationship between mother and daughter in MWP is evidently a problematic one, Kitty and Vivie nevertheless agree on one matter: none of them chooses to enter into the bond of marriage. Given the cultural context and the value of that institution, this depiction of women on stage certainly had a revolutionary touch. It strongly opposed the dominant Victorian discourse stating that "only in the married state [...] the boundless capabilities of a woman's love can be fully known or appreciated" (Ellis 110). Therefore, if this pivotal cultural concept 
is rejected, we expect the characters not to be able to perform their role anymore and thus lack the womanly love that is supposed to be so central to their personality. In this chapter, I will show, for one thing, that this refusal of marriage indeed has consequences for Kitty and Vivie and, for another, I will highlight that Shaw's drama at the same time criticises the underlying idea of marriage fundamentally.

As for Kitty Warren, we are not made privy to the details of her biography but have to examine the results of a somewhat unorthodox past: she has produced an illegitimate child, which from a Victorian perspective is bad enough, but she does not even show any form of regret or the willingness to find a husband after all. On the contrary, marriage, to her, seems entirely vacuous and, thus, does not say anything about a woman's respectability (MWP 66). Instead, Kitty has decided to provide for herself and to abandon the prospects of marital love in order to avoid being dependent on male patronage. However, what is interesting is that she refers to herself as 'Mrs' Warren anyway, although she is actually unmarried. Her justification for assuming that title is the simple fact that she is a mother (47). This is a central point because through the adoption of that name, Kitty, in fact, counteracts the social imperative dictating that procreation is allowed solely in the context of marriage. In her view, a woman is entitled to call herself 'Mrs', not only after having passed a marriage ceremony, but when becoming a parent, which obviously is very much at odds with Victorian thinking.

If we give credit to her daughter's words, however, we find yet another aspect that is of importance here: Vivie calls her mother, who is so keen on leading a self-determined life, "a conventional woman at heart" (104) and hence insinuates that Kitty is not actually able to live free from society's ideals. If she really "live[s] one life and believe[s] in another" (104), then Kitty's choice of name suggests that she does indeed seek some form of acceptance as an allegedly married woman in the society that she permanently condemns.

To support this, one can consider her relationship to Crofts which reveal a similar reservation about her rejection of social standards: Although Kitty has always objected to marrying a man, it is arguable that George Crofts does take over functions of a husband for her. On the one hand, they were lovers (41) and, on the other, support each other in making a living. Therefore, one can state that their bond allows her to experience a substitute for marital love and likewise it secures her financial situation. In this sense, it becomes clear that even a supposedly independent character like Kitty Warren finds herself to be somehow attached to those cultural webs that structure her society and assign meaning to an institution such as marriage. What this adds up to, however, is very striking: Kitty dismisses marriage in favour of her freedom and independence but still searches for the support and security that comes with it. Therefore, she even enters an alliance with a man such as Crofts who became rich through being "stingy" and "vicious" (58). 
Remarkably, Kitty Warren's relationship towards love and marriage, is not so different from her daughter's attitude: in order to uphold the gender role Vivie has negotiated for herself, she rejects all claims on her person and life, and instead declares candidly: "I don't want a husband" (103). Rather, it is through her work that she maintains her social rank and constitutes her identity as a woman. To stress that, she instantly makes clear she is not interested in any advances by either Praed (33) or Crofts (38) because just as in the case of her mother independence to Vivie seems crucial to survive. Like Kitty, she is not able to relate to the alluring prospects of Victorian marriage and neither does she have a parental relationship to look up to. Instead, it seems it is both her legacy and her own character that have made her develop an attitude that does not allow for matrimonial happiness. The consequence, however, that Vivie formulates herself, is a dire one: "Once for all, there is no beauty and no romance in life for me. Life is what it is; and I am prepared to take it as it is" (92). In order to live by this standard, she has to supress her emotional side $(93,95)$, though, and constantly has to be "merciless to herself' (93).

When looking at her relationship to Frank, however, we see that Vivie's refusal to bind herself to someone holds true only to a certain extent as well. The two of them, at least temporarily, indulge in an unusual romantic relationship by falling back into the roles of children (56). Only within this secret and protected imaginary world Vivie is able to experience a form of partnership, and during these moments both manage to escape from their parents' influence (77). To my mind, this yearning for a retreat into an innocent and private sphere clearly opposes the scholarly view of Laurence depicting Vivie as throughout "strong, determined, and apart, as all [of] Shaw's great women" (43). Instead, her character is equipped also with a rather vulnerable side beyond the superficial resoluteness.

In conclusion, both mother and daughter have an ambivalent relationship towards partnership: for one thing, they object to the concept of Victorian marriage out of the fear to lose their self-determination. Likewise, however, Kitty and Vivie do feel a longing for acceptance and affection that cannot be catered for within the context of conventional nineteenth-century forms of partnership. Therefore, both of them choose alternative ways, which in Shaw's world, again, is doomed to fail: Crofts turns out to be attracted by Vivie instead and hence completely falls out with Kitty (58). Frank, in turn, is not successful with his advances so that in the end their romantic alliance is downgraded to a brother-sister-relationship. As a result, we once more see a gendered concept such as marriage fail because as a Victorian convention it neither "reckon[s] with facts of human nature" (Reinert 17) nor does it permit any flexibility or alternatives. 


\subsubsection{The Female Comic Subversion}

At first glance, the representation of marriage in IBE seems quite contrary to that in MWP. In Wilde's play, everyone wants to marry at all costs and, as will become clear, the female characters pursue that goal in a quite peculiar manner. Later on, however, we will see that there is criticism in the Wildean comedy as well, which is not even far away from what has been said in the previous chapter.

To start with, what comes across as very typically Victorian is that all women in IBE are fully aware of the importance of being married. Lady Bracknell, for instance, has a quite pragmatic view on marriage and prioritises its material and social advantages (Eltis 191). Gwendolen and Cecily, on the other side, both aspire to find a "romantic boy" (IBE 58) to love "passionately" (21). However, looking at the criteria by which they select their partners reveals that the women's attitudes are not as conventional as they may seem: firstly, Gwendolen's mother approves of Algernon because "he has nothing, but he looks everything" (84). What makes Jack potentially eligible, in turn, is obviously his wealth but also that he smokes and says of himself he knows nothing rather than everything (25). If we take Lady Bracknell seriously in her speech, we have to constitute that these arguments are nothing more than a caricature of the Victorian must to study a man's "real character" before marrying and to ensure that he is morally upright (Ellis 17). In fact, she even expresses very blatantly that finding out about one's personality prior to marriage "is never advisable" (IBE 84), and thus she completely twists the meaning of Victorian wedlock around: in Lady Bracknell's view, marriage is not an intimate relationship between husband and wife but a social shell, a surface on which adherence to convention can be read off. Here, public performance of family gender roles clearly outranks the (alleged) substance of these conceptions.

As for Gwendolen and Cecily, one can observe that in comparison to Lady Bracknell they seem interested in a romantically idealised version of partnership. However, neither of them examines her potential husband carefully in the Victorian sense. What makes a man eligible in the young women's eyes is simply that he would bear the name Ernest. As a matter of fact, their love actually depends on nothing else: for Gwendolen, Ernest is "the only really safe name" (22), suggesting that the right surname could ensure a fulfilled married life. Cecily, in turn, states she would not be able to give "undivided attention" (59) to a man called anything other than Ernest. Thus, the success of romantic love is here based on something utterly irrelevant, which consequently makes the underlying concept of marriage look rather trivial and satirises the earnestness with which Victorians were supposed to pursue marriage, select their partners and live their married lives.

Moreover, not only are their men allowed any flaws except for the wrong name, Cecily and Gwendolen also grant themselves liberties that are contradictory to nineteenth-century wifely ideals: both make plain that even for the man they love, they are by no means willing to wait $(59 \mathrm{f}, 86,91)$ and hence act strongly 
against the idea of devoting one's love to one person only. Instead, Gwendolen freely admits "I never change, except in my affections" (93) and Cecily simply breaks off her self-made engagement to Algernon, although in Victorian England this would have been a disgrace for the family (Ellis 16). Even worse, when the two of them discover that their partners are not actually called Ernest, Cecily and Gwendolen's conclusion is simply that they have never been engaged at all (IBE 70). That is to say, the name in marriage appears to be more important than the actual person and neither of the women considers it necessary to look beyond that surface. Nevertheless, both still pretend to uphold Victorian standards and when they temporarily think they are competing for the same man, absurdly enough, the stage of this fight is a tea table and the weapons are sugar and cake (67).

To conclude, one can say that the actions of both parties, Lady Bracknell and the two young women, as different as they are, point in the same direction: to the outside, everyone pretends to be very keen on observing the proprieties when it comes to marriage. However, in all cases the standards the women apply to select a husband are highly comical, to say the least. Thus, the characters question the fundamental concept of marriage implicitly and illustrate its shallowness as their behaviour is all about the seeming and completely ignorant about anything that might be beneath that superficiality.

\subsubsection{Ineligible Marriage Partners}

We have seen that neither Vivie nor Gwendolen or Cecily are presented as typical Victorian wives-to-be. Turning now to the male suitors in the plays, it is notable that they neatly blend in with the women and do not cut a fine (gender) figure either. As to $M W P$, the striking observation is that even if Vivie did consider marrying, the drama would not feature anybody who fits the bill of a Victorian eligible marriage partner. Conversely, what we find in IBE are two dandies who throughout the play deconstruct the idea of a Victorian husband but are admired by their beloved anyway.

\subsubsection{Crofts and Praed}

Earlier I have argued that Frank Gardner, who is amongst the male characters in the play wooing Vivie, does not qualify as a Victorian husband because he lacks a sense of responsibility and instead of earning a living prioritises his own pleasure. When looking at the other two men showing an interest in Kitty's daughter, we find rather problematic characters as well. I will juxtapose Praed's and Crofts' gender performances by saying that the former is a man who is actually not man enough whereas the latter is virtually the opposite.

With Praed, we are presented with a character who, contrary to Vivie, is indeed looking out for "beauty and romance" in life (MWP 91). He is a sentimental man (38) who approaches life through art and aspires to soak up all the splendid 
things the world has in store $(35,92)$. Therefore, to him, even work is not primarily aimed at earning money but rather it is a means to gain culture (35). The reason he gives for this thirst for knowledge and cultivation is that he "was born a boy" and has never grown up (42). Hence, he loves walking with Vivie and trying "to stay out as long as possible" (52), which once more puts emphasis on this impression of a curious and somehow childlike personality.

The downside of this attitude is, however, that Praed always remains inside a sphere that is only partially coherent with the social setting that he finds himself in. As a matter of fact, when confronted with the real world, his shortcomings suddenly become apparent: he is described as "diffidently", "anxious and considerate" (92f) when Vivie challenges his art-loving disposition, and he rather shies away from confrontation instead of making his case. This sparsely masculine gender image is further deconstructed as he shows obedience towards the Vivie (93) and is not even able to express his discontent with the dinner arrangements at Kitty Warren's place (55). Here, a lack of assertiveness reveals that Praed does by no means fit into the notion of a strong-minded man who is capable of representing and protecting a family in the world of nineteenth-century England. Although he is a gentleman throughout and shows integrity in what he does, his overly polite fashion and his artistic worldview rather dawn on Vivie as a "disappointment as to the quality of his brains and character" (34). Even Frank, who is not exactly a man of the world either, perceives Praed as a romantic with a lost grip on reality (96). What this amounts to is the impression of a man who might be good-natured but in his artistic fragility would certainly not be able to lead a Victorian family as a husband.

In comparison to Praed, laying the focus on George Crofts reveals a very different kind of man: He is a character who has delved so deeply into a brutal world of work that retreating into the cosmos of a traditional nineteenth-century family does not seem possible anymore. His biography has taken him far away from the moral purity that Victorians perceived as a requirement for marriage. George Elliot, for example, felt that "only a person who had overcome the forces of worldliness in his or her own soul could safely marry" (Mintz 114). Crofts, however, in the play replies to this demand in a very pragmatic manner by saying: "while we're in the world we're in it" (MWP 78). In his view, a man has to adapt to the circumstances of a social reality that is not beautiful - as Praed would claim - but entirely corrupted (83). To do this, however, he has long abandoned the 'angelic' masculine gender image that his society demands. That is to say, he cannot claim those moral standards for himself that would qualify him as a suitable marriage partner for a Victorian woman and, strikingly enough, does not even try to. Against this background, Crofts' depicting himself as "a safe man from the money point of view" (79) exposes his rather one-dimensional idea of family: from his perspective, marriage provides a man with a lover, whereas he, in turn, offers money and status $(79,82)$. This functionalist understanding of Victorian wedlock, however, 
denies the moral fundament for a relationship that scholars have described as crucial.

What makes his eligibility as a husband appear even more questionable, however, is that are no signs of social criticism in his words. Crofts does not deplore injustice or moral decay but stresses the importance of finding a way to put up with it (83). As a practical man he knows the value of money as that one good that makes life more convenient and allows looking at the corrupted world from a safe position instead of having to suffer its badness. With this attitude, Crofts fails both from a Victorian perspective and in the eyes of Vivie. He draws upon the notion of a gentleman (82), pretends to woo her with "honest affection" (80) but quickly enough counteracts his own words: he sets Vivie under pressure and even reveals his violent streak (84). Likewise, he pretends to value fidelity and responsibility, which his past with Kitty Warren, however, does not support at all. Here, it becomes obvious that he has, in fact, become too much a part of a world in which morality, if anything, is a means to pursue personal profits.

All in all, while their competitor for Vivie's fondness, Frank, remains in the role of a rebellious son, Praed and Crofts are both men who walk the earth in spheres that are quite different but similarly non-Victorian. One is an artist lacking the strong-minded Victorian masculinity that was thought to be pivotal for protecting one's family from the outside. The other one is a businessman who has internalised the logic of a morally corrupted world to such an extent that the wealth and position he can offer still cannot make up for his obvious gender failure as a Victorian marriage partner.

\subsubsection{Jack and Algernon}

It was shown that all marriage plans in Shaw's drama fail, for one thing, because of Vivie's refusal and, for another, because of the gender shortcomings of all male characters. Considering what has been said about IBE already, it does not come as a surprise that Wilde, in turn, approaches the idea of courtship in quite a different manner: his prototype of a suitor in the play is an utterly un-Victorian "unreasonable man $[\ldots]$ who will think and act in a particular manner just because he will" and who declines any form of argument because its outcome would not change his mind anyway (Ellis 59). In Jack and Algernon, the theatre audience is presented with two men who may even look earnest on the surface (IBE 11) but in their speech and actions satirise their own roles very much. Both of them clearly deviate from the gender concept of a Victorian man and potential marriage partner in that their lives seem to be entirely and solely oriented at seeking pleasure (7). In fact, they subordinate all other values to this hedonistic maxim: Jack, for instance, states that morality takes its toll on one's happiness (13), and hence he frequently escapes from the social obligations of a guardian. Algernon, on the other side, is not one jot better, and whenever pleasure is at stake he pretends to look after his ill friend Bunbury (14). 
Contrary to $M W P$, it is in a very comical way that the two men undermine their own integrity and authority here. Algernon makes his butler lie about something as trivial as cucumber sandwiches (18) and Jack is the first to decide to simply have himself christened in order to get rid of his first name (49). All this does by no means conform to the notion of a virtuous Victorian gentleman. Admittedly, one has to constitute that Jack at least shows attempts to reform himself as he wants to 'kill' his imaginary brother (15), but then again these plans are only very limited. When being asked if he considers coming clean with Gwendolen about his lying to her, he claims that "the truth isn't quite the sort of thing one tells to a [...] girl" (31f). Thus, he objects to the Victorian idea that honesty would be "the only sure basis" for marriage (Ellis 17).

In addition to this, Algernon's view of marriage is even further away from nineteenth-century ideals: being married, in his eyes, is something demoralising that one rather wants to forget and instead it is divorces that "are made in heaven" (8). Remarkably, this socially quite incorrect and dandy-like worldview, to his mind, does not even oppose his "duty as a gentleman" (53). What this shows is that Algernon has managed to redefine his gender role in a way that he pretends to uphold Victorian family ideals but at the same time ducks all responsibilities. He comically disguises his gender deviation behind the term Bunburying and, strikingly enough, is even successful in legitimising his actions with it. That this applies to Jack in a similar way becomes clear when considering that Miss Prism and Reverend Chasuble think him to be an impeccable Victorian man $(38,47)$ and do not express any doubts about his integrity despite the fact that his alleged brother appears only a moment after Jack has pronounced him dead (47ff). Gwendolen, however, even discovers his foul play but simply decides to "crush" her doubts (76).

In fact, this is the most crucial thing to note about both Algernon and Jack: the two of them commit a strong "love breach" (Foster 21) and hence prove themselves to be ineligible Victorian marriage partners but this never causes them trouble for long in the play. Looking beyond the comical dimension of this fact reveals a serious form of social criticism: Algernon states that "a man who marries without knowing Bunbury has a very tedious time of it" (IBE 16) and hence implies that a fulfilled marriage is not even possible without deception. In this sense, his being serious about Bunburying (71) means that what is really of importance to Algernon is to step out of his role. But in this process "the Bunburying Algernon, in escaping the hypocrisy of convention, becomes a hypocrite himself by pretending to be somebody he is not" (Reinert 16). That is to say, fleeing from a corrupted social system in Wilde's drama is only possible through corrupting oneself once more. Therefore, if one follows Foster's statement that "fools must be taken seriously in the extra-rational world of Wilde's play" (19), then the failure of the two husbands-to-be rather casts a negative light on that very society that produces these comical actions. As a result, our laughter about their silliness can then be 
understood as "an effect of discrepancy" (Helbig 350). It is a reaction to something unexpected and based upon the knowledge about 'how things should be'. This intuition represents the deeply inscribed gender roles, here for a Victorian young man, which are humorously subverted and exposed as artificial.

\section{Flickers of Hope?}

So far, this paper has focused on the various ways in which the characters in IBE and $M W P$ act against Victorian family ideals and render those conceptions problematic. Going one step further, I is worth asking the question if the two dramatists offer any alternatives regarding the topics of family and gender in Victorian England. It is rather obvious that none of the plays features characters who successfully bear a non-conventional family role. However, there might be rudiments of hope hinting at alternative gender concepts or ways to better deal with society's expectations. Therefore, I will draw attention to those characters who - beyond their obvious flaws - manage to do something crucial: they reveal failures of the society they live in and likewise open up new forms of gendered behaviour and attitudes.

To start with, there is Frank who very aptly says about himself "I am not a fool in the ordinary sense" (MWP 91). Although he is presented as a good-fornothing character, he is, in fact, capable of seeing below the surface: to him, the concept of family needs some kind of essence and cannot be built simply around politeness (73). Frank makes very plain that, especially amongst family members, form must never rule over substance! This is why, from his own perspective, he has to be hard on his father. The reverend, in his eyes, is an epitome of hypocrisy striving for social acceptance in the family and beyond, but does not live by his own standards.

Even more importantly, though, Frank's great achievement in the play is that although he does not step into his father's gender role - he compensates Gardner's shortcomings and hence introduces a new dimension to the gender role of a Victorian son. Seeing his father lack social skills, he takes up the role of a host, shows the family's guests around and even introduces them to church, which clearly would have been the reverend's domain (72ff). Here, it seems that Frank has those talents that Gardner misses, thus gains authority and manages to somehow distinguish himself. Furthermore, his ideal of marriage is a relationship based on love and not on economic interests (53). Hence this concept of partnership seeks to satisfy, first and foremost, two partners and not the world around them. Moreover, even when the prospect of marrying Vivie dwindles, he ultimately shows a great deal of maturity and promises his support as a brother (96). Strikingly, it is therefore him - the 'fool' in the play - who manages to deal with gender failure best: despite the rejection of his love and without money or renown, in the 
end, he remains as a happy character for he has found a set of substantial values offering more than a merely a visible frame of conformity.

A second character who is able to free himself to some degree of social norms is Praed. He may not be a strong man in the Victorian sense, but as a libertine looks from a different perspective on his cultural setting. On the one hand, he is a perfect gentleman but then again questions Victorian thinking when he claims that "the most intimate human relationships are far beyond the law", that is, the demands of society (94). Quite vigorously, he denies any inherent value in paternal authority and dismisses gender images as obsolete and "nothing real" (34). What is striking in his character is that Praed rejects these gender categories that society imposes upon him, and yet, he does not attempt to completely break out of that system. Knowing that his identity is inextricably linked to the cultural webs of Victorianism, he chooses to focus on the slowly improving circumstances (34) and tries to evoke change from within: he takes Vivie "on her own merits", accepts Kitty despite her past, and even tries to restore at least part of a domestic happiness between the two women (41f). Therefore, just like Frank, he strives to do away with the social shallowness of Victorian relationships and instead puts emphasis on mutual trust and support.

In the comical and witty play of Oscar Wilde, in turn, it is the character of Cecily who is capable of even more than ridiculing convention: firstly, she understands that appearance does not actually reveal much about one's character and suspects that a wicked person "will look just like everyone else" (42). In addition, Cecily is fully aware that the dominant behavioural patterns of her time are inscribed on a "shallow mask of manners" (65) and hence are as vacuous as the phenotype of a person. Nevertheless, similarly to Gwendolen, she stays within her role to the outside and thus, given her age and the influence of her mother, shows a remarkable ability to challenge the rigid social structures of her environment out of an allegedly conformist position.

Moreover, Cecily also seems to have a sense for what limits the altering of one's own character: her statement that reforming oneself is rather Quixotic (44) highlights that she has realised the immense difficulty of shaking off one's socially grown identity. What sets her apart, however, is that she does, in fact, prove to be a self-possessed woman and able "to make her intentions quite clear" (Eltis 184). Her idea of social intercourse is that "whenever one has anything unpleasant to say, one should always be quite candid" (IBE 62). This surely opposes the demand of saving one's face at all times for the sake of an impeccable reputation. What is more, she shows her autonomy by choosing to be engaged to a man simply by deciding so without even asking him (56ff). Hence, Cecily undermines her expected role of a submissive young Victorian female. Instead of acting according to standard courtship procedures, she is looking out for a man who is explicitly not sensible as she imagines pleasure in being reckless $(45,42)$. Of course, one has to admit that she ultimately does not break with Victorianism. But in the comical 
reality of Wilde's play this is not even necessary anyhow because, as I stated earlier, social criticism is here hidden under the mask of humour.

In conclusion, these three characters make an important point in both plays: their behaviour and attitudes suggest that there is an actual chance to "disturb and rearticulate" gender roles, as Powell (101) describes it. All of them express their discontent with the prevalent family ideals of Victorianism and have managed to take first steps towards alternative forms of gender performance. Still, Frank and Praed come away empty-handed as far as their marriage plans are concerned, and Cecily is allowed to be successful only in the world of a drama that does not punish social deviance anyway. Hence, seeing their attempts to escape convention in the larger contexts of the plays, one can find flickers of hope but no clear perspective for better gender conceptions in the Victorian family.

\section{Conclusion}

Weaving together the observations about Victorianism and the way its demands are mirrored in the two dramas highlights the potential of criticism in both plays. With regard to New Historicism, we have seen plenty of evidence suggesting that the plays were written upon the basis of prevailing nineteenth-century gender conceptions for the family. This "cultural matrix" that Butler (24) speaks of sets the Victorian family at the centre of society and is omnipresent in the actions of all characters. The fact that Wilde and Shaw are playing with these gender expectations reveals that they were aware that conformist behaviour inside the family and in public is, of course, not innate but socially scripted and can hence be questioned.

However, it was difficult to voice any direct criticism - even more so on the stage -, especially as it was Queen Victoria herself, as well as her husband and children, who impersonated that family ideal. The Lord Chamberlain's Theatre censorship was a powerful instrument to prevent the spreading of subversive thought. Nevertheless, what the two playwrights do is to allude to those cracks in the social foundation, which Victorians perceived and which hence were identifiable for theatre audiences (Beckson 74). That is to say, Shaw and Wilde both situate their characters within Victorian spheres where they experience the difficulties coming with family gender prescriptions. Surely, the methods they use differ fundamentally: while Shaw deplores Victorianism, Wilde comically satirises it. The medium, however, is the same in both classes: it is on the surface of the nineteenth-century family that both criticise a society imposing a deficient gender system on its members.

In $M W P$, the results of this process are portrayed in a very serious manner. There is obvious parental failure on the part of Kitty Warren and Samuel Gardner, spreading across generations to their children. Even worse, though, not only are the relationships between parent and child spoilt but we also find Victorian mar- 
riage, which was to hold together the nineteenth-century family, to be deconstructed: contrary to the central gender expectations, the women in MWP refuse to marry at all, while all men fail as potential marriage partners because they lack either a sense of duty, integrity, or strong-mindedness. It becomes clear, though, that Shaw does not primarily blame individuals here but rather the system that sets unrealisable gender standards in the first place.

Regarding IBE, there is - as Shaw lamented - no obvious moral point in the play. This paper, however, defends Wilde's work against Shaw's criticism in as much as it stresses the potential of humour for social criticism. In the drama, we find Lady Bracknell as the paragon of Victorianism, who is oblivious to her own comical exaggeration. Then there are two dandies who despite their lies and deception, consider themselves perfect gentlemen. Lastly, as to Gwendolen and Cecily, they are both acting out their gender roles half jokingly and merely for appearances' sake. Strikingly enough, though, in the world of IBE even obvious non-conformist gender performance is never disciplined in any way because "reason is ruled out" (Thienpoint 249). Therefore, the fact that ultimately everything falls into place in $I B E$ is perhaps not a weakness, but the greatest strength of the play! It suggests that familial happiness in the Victorian gender system is indeed only possible in a comical reality. The characters' gender failure, in this sense, is in line with Eltis - not merely owed to "pervasive flippancy" (171) but it constitutes an escape from a merciless society into absurdity. Hence, the laughter that the play evokes then becomes "a subversive act in view of inadequate discourses" (Helbig 352). That is, audiences laugh at incongruent gender ideals and hence reveal their artificiality.

Of course, the perspective of gender and family is only one amongst others suitable to reveal social criticism in the two plays. For future research, it would be promising, for instance, to examine family ideals by means of Foucault's discourse analysis. Moreover, within the scope of this thesis it was not possible to examine all characters and scenes in greater detail. Rather, I focused on the central parts and speeches that allowed me to locate the character's actions in the larger picture of nineteenth-century family concepts.

Finally, in spite of some flickers of hope, it has to be noted that the plays both paint a rather bleak picture of Victorian family: they expose the "fundamental unnaturalness" of gender (Butler 203) and reveal that those roles that society provides are strongly at odds with the realities of the characters. Even worse, family ideals are hence not only destructive as such, but likewise breaking out of that system is doomed to fail - in $M W P$ - or can only work out when characters flee into a comical reality - in IBE. Either way, both Shaw and Wilde criticise that society fails at its core if families are corrupted - the more so as the family was a concept of key importance in nineteenth-century England. 


\section{Works Cited}

Allan, J. M. (1869) “On the Differences in the Minds of Men and Women." Journal of the Anthropological Society of London 7, cited in P. Jalland and J. Hooper, Women from Birth to Death. The Female Life Cycle in Britain 1830-1914. Brighton: Harvester, 1986.

Archer, William. (1895) “On The Importance of Being Earnest." Oscar Wilde. The Importance of Being Earnest. Authoritative Text, Backgrounds, Criticism. Ed. Michael Patrick Gillespie. New York \& London: W.W. Norton \& Company, 2006.

Beckson, Karl. "London in the 1890s." Oscar Wilde. The Importance of Being Earnest. Authoritative Text, Backgrounds, Criticism. Ed. Michael Patrick Gillespie. New York \& London: W.W. Norton \& Company, 2006.

Brecht, Bertolt. Der gute Mensch von Sezuan. Frankfurt am Main: Suhrkamp, 2003.

Butler, Judith. Gender Trouble. Feminism and the Subversion of Identity. New York and London: Routledge, 2008.

Deaux, Kay, and Mary E. Kite. "Thinking About Gender." Analyzing Gender. A Handbook of Social Science Research. Ed. Beth B. Hess and Myra Marx Ferree. Newbury Park: Sage, 1987. 92-117.

During, Simon. "New Historicism.” Text and Performance Quarterly. 11.3 (July 1991): 171-189.

Ellis, Sarah Stickney. The Wives of England, Their Relative Duties, Domestic Influence and Social Obligations. New York: D. Appleton and Co, 1843.

Eltis, Sos. Revising Wilde. Society and Subversion in the Plays of Oscar Wilde. Oxford: Oxford University Press, 1996.

Farningham, Marianne. Home Life. London: James Clarke \& Co., 1889.

Flanders, Judith. The Victorian House. Domestic Life from Childbirth to Deathbed. London: HarperCollinsPublishers, 2003.

Foster, Richard. "Wilde as Parodist: A Second Look at the Importance of Being Earnest.” College English 18.1 (October 1956): 18-23.

Fyfe, Hamilton. (1895) "On The Importance of Being Earnest." Oscar Wilde. The Importance of Being Earnest. Authoritative Text, Backgrounds, Criticism. Ed. Michael Patrick Gillespie. New York \& London: W.W. Norton \& Company, 2006.

Gallagher, Catherine, and Stephen Greenblatt. Practicing New Historicism. Chicago: University of Chicago Press, 2000. 
Geertz, Clifford. "Thick Description. Towards an Interpretative Theory of Culture." The Interpretation of Culture. New York: Basic Books, 1973. 3-30.

Glenn, Evelyn Nakano. "Gender and the Family." Analyzing Gender. A Handbook of Social Science Research. Ed. Beth B. Hess and Myra Marx Ferree. Newbury Park: Sage, 1987. 348-380.

Gordon, Eleanor, and Gwyneth Nair. Public Lives. Women, Family and Society in Victorian Britain. New Haven \& London: Yale University Press, 2003.

Greenblatt, Stephen. The Powver of Forms in the English Renaissance. Norman, OK: Pilgrim, 1982.

---. The Greenblatt Reader. Ed. Michael Payne. Oxford: Blackwell 2005.

Helbig, Volker. "Judith Butler and the Problem of Adequacy, or: The Epistemological Dimension of Laughter." Gender and Laughter. Comic Affirmation and Subversion in Traditional and Modern Media. Ed. Gaby Pailer et al. Amsterdam \& New York: Rodopi, 2009.

Hess, Beth B., and Myra Marx Ferree, ed. Analyzing Gender. A Handbook of Social Science Research. Newbury Park: Sage, 1987.

Ittmann, Karl. Work, Gender and Family in Victorian England. New York: New York University Press, 1995.

Laurence, Dan H. "Victorians Unveiled: Some Thoughts on Mrs Warren's Profession." SHAW: The Annual of Bernard Shaw Studies 24 (2004): 38-45.

Marshik, Celia. British Modernism and Censorship. Cambridge: Cambridge University Press, 2006.

Mintz, Steven. A Prison of Expectations. The Family in Victorian Culture. New York \& London: New York University Press, 1983.

Nelson, Claudia. Family Ties in Victorian England. Westport: Prager, 2007.

Nelson, Raymond S. "Mrs. Warren's Profession and English Prostitution." Journal of Modern Literature 2.3 (1971/1972): 357-366.

Powell, Kerry. Acting Wilde: Victorian Sexuality, Theater, and Oscar Wilde. Cambridge: Cambridge University Press, 2009.

Reinert, Otto. "Satiric Strategy in The Importance of Being Earnest." College English 18.1 (October 1956): 14-18.

Robson, Mark. Stephen Greenblatt. New York: Routledge, 2008.

Ruskin, John. Sesame and Lilies. Boston: Houghton Mifflin, 1865. 
Shaw, George Bernard. (1918) "My Memories of Oscar Wilde." Oscar Wilde. A Collection of Critical Essays. Ed. Richard Ellmann. Englewood Cliffs: PrenticeHall, 1969. 92-106.

Shaw, George Bernard. Mrs. Warren's Profession. [MWP]. Seaside, Oregon: Watchmaker Publishing, 2010.

Shellard, Dominic, Steve Nicholson, and Miriam Handley. The Lord Chamberlain regrets ... A History of British Theater Censorship. London: The British Library, 2004.

Shires, Linda M., ed. Rewriting the Victorians. Theory, History and the Politics of Gender. New York and London: Routledge, 1992.

Shuttleworth, Sally. "Demonic Mothers. Ideologies of Bourgeois Motherhood in the Mid-Victorian Era." Rewriting the Victorians, Theory, History and the Politics of Gender. Ed. Linda M. Shires. New York and London: Routledge, 1992.

Smiles, Samuel. Self-Help. New York: Harper and Brothers, 1871.

Stephens, John Russel. The Censorship of English Drama 1824-1901. Cambridge: Cambridge University Press, 1980.

Thienpont, Eva. "From Faltering Arrow to Pistol Shot: The Importance of Being Earnest." Cambridge Quarterly 33.3 (2004): 245-255.

Veeser, Harold Aram, ed. The New Historicism, London \& New York: Routledge, 1989.

Wilde, Oscar. "The Soul of Man under Socialism." Fortnightly Review 49.290 (February 1891): 292-319.

Wilde, Oscar. The Importance of Being Earnest. [IBE]. Stuttgart: Reclam, 2010. 